\title{
Why the Anthropocene Has No History: Facing the Unprecedented
}

\author{
Zoltán Boldizsár Simon
}

This is a draft version

For the published article follow the link to

\section{The Anthropocene Review 4:3 (2017), 239-245.}

\begin{abstract}
This essay argues that the tendency to invoke modern historical thinking in trying to make sense of the Anthropocene amounts to an untenable, self-contradictory, and selfdefeating enterprise. There is a fundamental contradiction between the prospect of unprecedented change as entailed by the Anthropocene and the deep continuity of a processual historical change. On the one hand, conceiving the Anthropocene as the prospect of the unprecedented creates a demand for immediate action to prevent future catastrophe. On the other hand, pointing out the inequalities in the historical process of bringing about the Anthropocene creates a demand for social justice. Although both are legitimate and important demands, they are incompatible. They represent different temporalities, different conceptions of change, and different modes of action. Inasmuch as the Anthropocene appears as unprecedented, it does not have a processual history; and inasmuch as it has a processual history, it is not the Anthropocene.
\end{abstract}

\section{Keywords}

Anthropocene, historical thinking, history, social justice, preventive action, unprecedented change 
The notion of the Anthropocene conquered the humanities at an extraordinary pace. At its inception, it marked a geological epoch of human-induced change, but it quickly transformed into a far broader concept. Since the landmark article of Dipesh Chakrabarty (2009), even historical studies were captivated by the notion of the Anthropocene, despite the reputation of the discipline as not being the utmost academic innovator. The appeal of the notion is due to the fact that historical studies, like many of its fellow disciplines in the humanities, became professionalized and institutionalized as the study of human beings. If Foucault (2002) is right in claiming that the so-called human sciences of modernity constituted the human as their shared object of knowledge, then it hardly comes as a surprise that the Anthropos (human in Greek) of the Anthropocene resonates with these disciplines. More surprising is the speed with which the Anthropocene has spread over the disciplinary landscape and the magnitude of the claims attached to the notion.

As to the ferocious tempo, there is a rapidly increasing number of articles and books devoted to the question of what happens to a particular subject in (the age of) the Anthropocene'. A title-based search in Google Scholar promptly reveals that 'archeology' (Lane 2015) and 'doing interdisciplinary Asian studies' (Philip 2014) are suddenly 'in the age of the Anthropocene' today, while 'digital humanities' (Nowviskie 2015), 'culture, environment, and education', (Greenwood 2014) or 'history and biology' (Thomas 2014) find themselves simply 'in the Anthropocene'. As to the tectonic claims, they are related to the aforementioned invocation of the Anthropos. For if the Anthropocene has to do with the Anthropos, and if history and its fellow disciplines have the human as their shared object of knowledge, then the claims of these disciplines must concern the figure of the human. In the humanities and social sciences, the Anthropocene indeed appears accompanied by claims no smaller than it offers a reconceptualization of the human condition (Palsson et al. 2013) or that it introduces a 'human turn' (Raffnsøe 2016).

Oddly enough, the human component also constitutes the biggest obstacle to the acknowledgment of the Anthropocene as an Anthropo-cene. After decades of postcolonial and gender criticism targeting the idea that there could be a 'humanity' or 'human being' as the unitary subject of an overall historical process, the implicit universalism of the Anthropocene often has a repulsive effect. Dipesh Chakrabarty who had an eminent role in dismantling Western universalism - is acutely aware of the fact that the simultaneous appeal to an inherently universal notion and to postcolonial criticism results in a dilemma. When introducing the notion of the Anthropocene to 
historical studies, Chakrabarty (2009: 219-220) captured it in the following question: 'how do we relate to a universal history of life - to universal thought, that is - while retaining what is of obvious value in our postcolonial suspicion of the universal?'

Whereas Chakrabarty (2014) still struggles with trying to resolve the dilemma, much of humanities and social science research chooses either the rejection or the approval of universalism. Both choices are apparent in the tendency to propose alternative names for the Anthropocene. According to already influential arguments, the notion in its current form enshrouds social, cultural, and political inequalities effective in bringing about the broader condition otherwise associated with the Anthropocene. Hence it would be more accurate to talk about the Technocene (Hornborg 2015) or the Capitalocene (Moore 2017). By invoking technology and capitalism as notions more sensitive to inequalities, these alternatives offer powerful corrections to the universalism of the Anthropocene. At the same time and on the other edge of the spectrum, the idea of a Cosmopolocene (Delanty and Mota 2017) affirms universalism by assuming that the Anthropocene provides the condition of possibility for the establishment of a global and truly cosmopolitan politics. Contrary to appearance, the Cosmopolocene is very far from being the complete opposite of the Technocene and the Capitalocene. It is rather their supplement that attributes a desired future direction to the same socio-political development whose past is outlined by the Capitalocene and the Technocene. Whereas the latter notions point to the origins of a present condition in terms of inequality, the Cosmopolocene entails a normative take on how the very same inequality may be overcome in future.

It can easily be seen how these alternative names intend to add new dimensions to our understanding of what natural sciences came to call the Anthropocene. Regardless of whether one agrees or not with the particular ethical and political take of any of the individual alternatives, their work is indispensable in thematizing the relationship between the social world and nature from the viewpoint of the former. But is the case the same as seen from the natural sciences? Does geology know inequality among humans? Is a geological or an ecological perspective capable of distinguishing which humans under what socio-political conditions brought about the Anthropocene in the first place? Should it be capable? Or, at the most general, does it matter to nature (as we conceive of nature) that along certain human conceptualizations of social divisions certain humans are greatly responsible for launching the Anthropocene, while others are not? And even if it did, would it be the reigning natural scientific understanding of the Anthropocene (which criticism in the 
humanities would identify again as specifically Western) to which all the alternative names add new dimensions? Or would it be rather a parallel discourse?

These are, I believe, deeply troubling questions. Yet it seems to me that talking about the Technocene, the Capitalocene or the Cosmpolocene amounts to, simply and plainly, talking about something other than the Anthropocene. They are not alternative names for the same thing, but names for entirely different and yet heavily interconnected things and phenomena. Even when the name is retained, the humanities and the social sciences debate things that are different in kind while they both appear to debate the Anthropocene. Despite the fact that in the larger debate both natural and human sciences appeal to the satisfaction of wider societal concerns, the respective concerns conflict and thus seem incompatible.

To unpack the situation, the conflict boils down to contradictory sets of societal demands. On the one hand, the necessity to recognize the Anthropocene as an epochal transformation in nature (and the way in which nature changes) is based on a future prospect. In this prospect, human activity transforms the environmental conditions to the extent that the planet becomes either hardly habitable or wholly inhabitable by humans. An indicative example of a future scenario of partial human extinction is outlined by Oreskes and Conway (2014), demanding action by sketching a history written from the viewpoint of a fictitious catastrophic future in which the human population of Australia and Africa go extinct. The worst case scenario is, however, the prospect of a wholesale human extinction, which is precisely what motivated Chakrabarty (2009: 197-198) to engage with human-induced climate change in the first place. Either way, this future prospect creates a demand for preventive action, accompanied by a strong sense of urgency. Furthermore, all this qualifies as an 'anthropogenic existential risk', a term borrowed from Nick Bostorm (2013: 16). Although Bostrom reserves the most threatening prospect of extinction that arises out of human activity for potential technological innovations, it stands to reason that the future entailed by the Anthropocene is just as much an existential risk as the future entailed by artificial intelligence research.

Contrary to this, debates about the Technocene, the Capitalocene, and even discussions under the retained name of the Anthropocene in the humanities and social sciences, are based on the primacy of a retrospective stance. Such a stance looks backward in time in order to explain how the current state of affairs has developed out of past conditions. The Cosmopolocene adds to this operation a maintained utopian imperative in the shape of a desirable future cosmopolitanism. On the one hand, it 
counters the natural scientific future prospect of the Anthropocene as catastrophic; on the other, just as the Technocene and the Capitalocene, it reserves the catastrophic take for the past. For it is only with comparison to the past that the future may look better, which clearly points to the imperative implied by these alternative names: the demand for social justice. Whereas the Technocene and the Capitalocene point to the roots of social injustice, the Cosmopolocene also imagines a future condition in which social justice may be reached. The normative condition of social justice may be different for practically any individual conceptualization. What binds all of them together is not their particular stance on what constitutes social justice, but the sheer fact that they either tacitly or deliberately demand such justice in one form or another.

However, the difference between the diverging imperatives of the ways in which the humanities and the natural sciences conceptualize human-induced climate change is most apparent in their views on the character of required agency. The demand for social justice relies on a mode of action completely different than what the demand for preventive action calls for. Whereas the former urges action in order to realize a desired outcome, the latter calls for action as a response to a threat posed by an undesired future. In other words, whereas the demand for social justice constitutes a proactive mode of action, the demand for preventive action is - by definition - a reactive one. Both demands and modes of action are legitimate and important, but they seem utterly incompatible.

Now, in what sense exactly are these demands incompatible? It must be clear that the incompatibility does not mean that the concerns of the demands do not meet in any sense whatsoever. First of all, both ground their respective calls for societal engagement in the present impact of human activity on natural activity. What is more, despite their respective focus in the past and in the future, both demands invoke both the past and the future to a certain extent. As mentioned earlier, a retrospective stance seeking for social justice implies a future in which such justice can be reached. Similarly, a prospective stance urging preventive action implies a past state of affairs compared to which the future appears as radically other. Hence the diverging demands are deeply connected in that they both invoke a conception of change over time that encompasses past, present, and future state of affairs. However, what seems to bind them together is precisely what ultimately sets them apart. For, on a more primordial level, the diverging demands and modes of action rely on two different temporalities and thereby two different conceptions of change over time. Whereas the demand for immediate action revolves around a temporality of what I have conceptualized elsewhere as unprecedented change (Simon 
2015), the demand for social justice is grounded in the processual change of modern (Western) historical sensibility.

To begin with the latter, critics of the notion of the Anthropocene are well aware of the fact that what they recourse to is historical thinking. Malm and Hornborg (2014: 63) are explicit in that it is 'the historical origins of anthropogenic climate change' that 'were predicated on highly inequitable global processes from the start'. Similarly, Moore (2017: 594) already makes it clear in the abstract that arguing for the Capitalocene means nothing other than arguing 'for the centrality of historical thinking in coming to grips with capitalism's planetary crises of the twenty-first century'. Finally, in a complementary manner, when advocating the universalist idea of the Cosmopolocene, Delanty and Mota (2017: 11) state that it is insofar as 'consciousness of the new human condition enters into historical self-understanding' that the Anthropocene 'can be seen as a new cultural model that is constitutive of a new object of knowledge and an order of governance'.

Invoking the modern concept of history and historical thinking in trying to make sense of the Anthropocene amounts to the creation of a historical trajectory into which the Anthropocene (Capitalocene, Technocene, Cosmopolocene) can be accommodated as a new stage of a long-term development. It amounts to the creation of a deep temporal continuity by assuming that a particular event or phenomena perceived as something new makes sense only as seen within a larger historical process. According to the philosophical investigations of Hannah Arendt into the modern concept of history, conceiving of change as processual both in nature and in the domain of human affairs is what 'separated the modern age from the past more profoundly than any other single idea' (Arendt 1961: 63). This processual temporality underlying the modern Western concept of history, rather obviously, also informs the discipline of history as a study of human beings. For Chakrabarty (2009: 197), it means that 'the discipline of history exists on the assumption that our past, present, and future are connected by a certain continuity of human experience.' And the challenge of the Anthropocene is precisely that 'the current crisis can precipitate a sense of the present that disconnects the future from the past by putting such a future beyond the grasp of historical sensibility' (Chakrabarty 2009: 197).

What this means is that the challenge of the Anthropocene's future prospect is a challenge to nothing other than modern historical thinking itself. In such a prospect, the Anthropocene appears as rupture as Hamilton (2016) argues, although for Hamilton it is not the vision of the future that introduces the rupture. Nevertheless, 
what the rupture entails is the same: the sudden occurrence of a novelty that is not the result of a continuous long-term development that originates in the deep past. This is what I call the prospect of unprecedented change, the prospect of a singular event expected to defy all previous human experience. It appears as the ultimate threat insofar as the future becomes incomprehensible to human cognition, due to the possibility of losing control over what originally was a human-induced change. The possibility of reaching a point when nature takes over anthropogenic climate change is the singular event whose consequences are inaccessible not only to human cognition, but inasmuch as all previous human experience is defied, even to human imagination.

By unprecedented change, however, I do not mean merely a synonym for the future prospect of the Anthropocene. The concept is intended to encompass perceptions of change over time not only in the geological and ecological domains but also in the realm of technology (Simon 2018). For it must be clear that 'the age of the Anthropocene' is not the only 'age' that appears as unprecedented today. The 'information age' following the 'digital revolution' or the 'atomic age' may be the most obvious instances of a postwar tendency to perceive of the future as promising to bring about something unprecedented. Like the Anthropocene, these prospects also entail the eradication of human life at worst or the sudden alteration of it beyond recognition at best. The prospect of global nuclear warfare appears just as much unprecedented as the prospect of human extinction entailed by the Anthropocene. But the most illustrative example is the creation of a non-human but greater-than-human superintelligence, which is conceptualized by Vernor Vinge (1993) as 'technological singularity'. It is likely followed by an 'intelligence explosion' of greater-than-human intelligence creating even greater non-human intelligence with unimaginable speed. As a sudden singular event, it also entails the prospect of losing control of an originally human-induced activity, with possible consequences impenetrable to the human mind.

Although for the time being technological singularity belongs to the realm of mere speculation, the effects of anthropogenic climate change are already felt. Hence the vision of the future entailed by the notion of the Anthropocene is far more tangible than other prospects of unprecedented change. When the humanities and social sciences invoke modern historical thinking in trying to make sense of it, they do more damage than good to its recognition. By creating deep continuities of historical trajectories, they incapacitate the demand for immediate and preventive action that derives from the prospect of the unprecedented. Some historians are very well aware of such perils within their craft. As Libby Robin (2013: 336) warns, historians 'can 
“discount the present" by providing a deep past'. In the case of the Anthropocene it is nevertheless the future and its perceived threat that can be discounted by modern historical thinking. What this means is that the deeper and longer-term history of the Anthropocene one tries to write, the deeper and longer continuity one implies and the farther away one moves from a sense of urgency for action. The less one thinks that what one faces is the unprecedented, the more one thinks that all this is business as usual. The deeper one looks into the past to find the origin out of which the Anthropocene develops, the more one thinks that this is how things have always been.

In the final analysis, modern historical thinking - once a vehicle of social change and social action - appears today as an obstacle to the recognition of newly emerging concerns which revolve around a completely different conception of change and mode of action. However, this is not to say that modern historical thinking is an obstacle to every change; it is still the condition of possibility of social emancipation. Nor is this to say that anything that qualifies as history and historical thinking is an obstacle. This is only to say that the modern (Western) conception of history which ideas like the Technocene, the Capitalocene or the Cosmopolocene rely on is an obstacle to the recognition of the Anthropocene as unprecedented.

Yet, in principle, nothing excludes the possibility to conceptualize another notion of history capable of recognizing the unprecedented. After all, it is still about change over time in human affairs. In fact, historians and philosophers of history are already engaged in the task of conceptualizing a historical sensibility other than processual (Runia 2006; Lorenz and Bevernage 2013; Simon 2016; Kleinberg 2017). Accordingly, the claim I wish to make is restricted to the still-dominant mode of historical thinking and it goes as follows: attempting to write the history of the Anthropocene by invoking modern processual historical thinking is an untenable, selfcontradictory, and self-defeating enterprise. For inasmuch as the Anthropocene appears as unprecedented, it does not have a processual history; and inasmuch as it has a processual history, it is not the Anthropocene (but the Capitalocene, the Technocene or the Cosmopolocene). 


\section{References}

Arendt H (1961) The Concept of History: Ancient and Modern. In Arendt H Between

Past and Future: Six Exercises in Political Thought. New York: The Viking Press. pp. 4190.

Bostrom N (2013) Existential Risk Prevention as Global Priority. Global Policy 4: 1531.

Chakrabarty D (2009) The Climate of History: Four Theses. Critical Inquiry 35: 197222.

Chakrabarty D (2014) Climate and Capital: On Conjoined Histories. Critical Inquiry 41: $1-23$.

Delanty G and Mota A (2017) Governing the Anthropocene: Agency, Governance, Knowledge. European Journal of Social Theory 20: 9-38.

Foucault M (2002) The Order of Things: An Archaeology of the Human Sciences. London and New York: Routledge.

Greenwood DA (2014) Culture, Environment, and Education in the Anthropocene. In Mueller MP, Tippins DJ and Stewart AJ (eds) Assessing schools for generation R (Responsibility): A Guide for Legislation and School Policy in Science Education. Dordrecht: Springer, pp. 279-292.

Hamilton C (2016) The Anthropocene as Rupture. The Anthropocene Review 3: 93-106.

Hornborg A (2015) The Political Ecology of the Technocene: Uncovering Ecologically Unequeal Exchange in the World-System. In Hamilton C, Bonneuil C and Gemenne C (eds) The Anthropocene and the Global Environmental Crisis: Rethinking Modernity in a New Epoch. London and New York: Routledge, pp. 57-69.

Kleinberg E (2017) Haunting History. Stanford: Stanford University Press. 
Lane PJ (2015) Archaeology in the Age of the Anthropocene: A Critical Assessment of its Scope and Societal Contributions. Journal of Field Archaeology 40: 485-498.

Lorenz C and Bevernage B (eds) (2013) Breaking Up Time: Negotiating the Borders between Present, Past and Future. Göttingen: Vanderhoeck \& Ruprecht.

Malm A and Hornborg A (2014) A Geology of Mankind? A Critique of the Anthropocene Narrative. The Anthropocene Review 1: 62-69.

Moore JW (2017) The Capitalocene, Part I: On the Nature and Origins of Our Ecological Crisis. The Journal of Peasant Studies 44: 594-630.

Nowviskie B (2015) Digital Humanities in the Anthropocene. Digital Scholarship Humanities 30 (suppl_1): i4-i15.

Oreskes N and Conway EM (2014) The Collapse of Western Civilization: A View from the Future. New York: Columbia University Press.

Raffnsøe S (2016) Philosopby of the Anthropocene: The Human Turn. Basingstoke: Palgrave.

Palsson G et al. (2013) Reconceptualizing the "Anthropos" in the Anthropocene: Integrating the Social Sciences and Humanities in Global Environmental Change Research. Environmental Science and Policy 28: 3-13.

Philip K (2014) Doing Interdisciplinary Asian Studies in the Age of the Anthropocene. The Journal of Asian Studies 73: 975-987.

Robin L (2013) Histories for Changing Times: Entering the Anthropocene? Australian Historical Studies 44: 329-340.

Runia E (2006) Presence. History and Theory 45: 1-29.

Simon ZB (2015) History Manifested: Making Sense of Unprecedented Change. European Review of History 22: 819-834. 
Simon ZB (2016) We Are History: The Outlines of a Quasi-Substantive Philosophy of History. Rethinking History 20: 269-279.

Simon ZB (2018) History Begins in the Future: On Historical Sensibility in the Age of Technology. In Helgesson S and Svenungsson J (eds) The Ethos of History: Time and Responsibility. Oxford and New York: Berghahn. (forthcoming)

Thomas JA (2014) History and biology in the Anthropocene: Problems of scale, problems of value. The American Historical Review 119: 1587-1607.

Vinge, V (1993) The Coming Technological Singularity: How to Survive in the PostHuman Era. In Vision-21: Interdisciplinary Science and Engineering in the Era of Cyberspace, Proceedings of a symposium cosponsored by the NASA Lewis Research Center and the Ohio Aerospace Institute, pp. 11-22. 